\title{
Perceptions of the 2011 ACGME duty hour requirements among residents in all core programs at a large academic medical center
}

\author{
Benjamin J. Sandefur ${ }^{1 *}$, Diana M. Shewmaker ${ }^{1}$, Christine M. Lohse ${ }^{2}$, Steven H. Rose ${ }^{3}$ and James E. Colletti ${ }^{1}$
}

\begin{abstract}
Background: The Accreditation Council for Graduate Medical Education (ACGME) implemented revisions to resident duty hour requirements (DHRs) in 2011 to improve patient safety and resident well-being. Perceptions of DHRs have been reported to vary by training stage and specialty among internal medicine and general surgery residents. The authors explored perceptions of DHRs among all residents at a large academic medical center.

Methods: The authors administered an anonymous cross-sectional survey about DHRs to residents enrolled in all ACGME-accredited core residency programs at their institution. Residents were categorized as medical and pediatric, surgery, or other.

Results: In total, 736 residents representing 24 core specialty residency programs were surveyed. The authors received responses from 495 residents (67\%). A majority reported satisfaction (78\%) with DHRs and believed DHRs positively affect their training (73\%). Residents in surgical specialties and in advanced stages of training were significantly less likely to view DHRs favorably. Most respondents believed fatigue contributes to errors (89\%) and DHRs reduce both fatigue (80\%) and performance of clinical duties while fatigued (74\%). A minority of respondents (37\%) believed that DHRs decrease medical errors. This finding may reflect beliefs that handovers contribute more to errors than fatigue (41\%). Negative perceived effects included diminished patient familiarity and continuity of care (62\%) and diminished clinical educational experiences for residents (41\%).
\end{abstract}

Conclusions: A majority of residents reported satisfaction with the 2011 DHRs, although satisfaction was significantly less among residents in surgical specialties and those in advanced stages of training.

Keywords: Duty hour, Fatigue, Medical education, Medical error, Resident perception, Work hour

\section{Background}

In 1999, the Institute of Medicine released a landmark report, "To Err Is Human: Building a Safer Health System," which implicated medical errors as a principal cause of patient morbidity and mortality [1]. The report concluded that deaths due to preventable medical errors exceeded deaths attributed to motor vehicle accidents, breast cancer, or acquired immunodeficiency syndrome. In 2003, the Accreditation Council for Graduate Medical Education (ACGME)

\footnotetext{
* Correspondence: sandefur.benjamin@mayo.edu

${ }^{1}$ Department of Emergency Medicine, Mayo Clinic, 200 First St SW, Rochester, MN 55905, USA

Full list of author information is available at the end of the article
}

instituted duty hour requirements (DHRs) as a component of common standards governing resident education, with the goal of improving patient safety and resident well-being. The standards required a limit of 80 weekly work hours averaged over 4 weeks, a limit on continuous duty of $24 \mathrm{~h}$ with an additional $6 \mathrm{~h}$ for transfers of care, 1 day off in every 7 , and a limit on in-house call to once in every 3 nights [2, 3]. In 2008, the Institute of Medicine published "Resident Duty Hours: Enhancing Sleep, Supervision and Safety," which recommended enhanced monitoring of duty hours, regulation of resident caseloads, enhanced supervision, and improved transitions of patient care, or handovers, and simultaneously acknowledged an 
absence of crucial research investigations [4]. The ACGME implemented revised standards in 2011 to more closely regulate duty hours and trainee supervision. Among the new regulations were a limit of 16 contiguous work hours for first-year trainees, a limit of $4 \mathrm{~h}$ for transfer of care after a 24-h work period, a recommendation of $10 \mathrm{~h}$ off duty (required $8 \mathrm{~h}$ off duty) between duty periods, and requirements for improved handovers of care and supervision of residents [5].

Performance impairment due to sleep deprivation and fatigue is well established [6-8]. However, the effects of the ACGME DHRs on resident well-being and education, as well as patient safety, continue to be debated. Some studies have suggested that DHRs are beneficial for alertness [9] and are supported by residents [10, 11]; other studies have raised concerns about adverse effects on clinical training $[12,13]$ and overall quality of patient care $[13,14]$. One structured review of the empirical literature on duty hour limits and patient care and resident outcomes found that existing studies assessing safety and quality in teaching institutions have yielded heterogeneous results [15]. Studies demonstrating positive effects of DHRs were more likely to have been conducted in medical specialties, while those conducted within surgical disciplines raised concern about the negative effects of DHRs on patient safety and continuity of care [15].

Determining the impact of DHRs on a complex system of medical education and health care delivery continues to be an important area of scholarship. Improving our understanding of residents' attitudes and opinions about DHRs may provide valuable insights. Philibert [16] reported that programs in which residents view duty hour compliance as a strength are characterized as more efficient, collegial, and responsive to problems. Existing literature suggests that there may be heterogeneity in perceptions of DHRs among the specialties and the stages of training, as highlighted by a recent study demonstrating that internal medicine respondents favored DHRs more than general surgery respondents among a subset analysis of 49 respondents at 1 institution. In addition, in this study, first-year residents viewed DHRs in a more positive manner than senior residents and faculty [17].

Our anecdotal experience from a large academic medical center with 736 residents enrolled in 24 ACGME-accredited core residency programs suggests that residents generally view DHRs positively, though with coinciding concerns over lost educational opportunities. In this study, we aimed to explore resident satisfaction with the ACGME DHRs and perceptions of the impact of DHRs on patient care, their education, fatigue mitigation, and medical errors. We also aimed to explore differences in satisfaction with DHRs and perceptions of the overall effects of DHRs on training by specialty type and stage of training. We hypothesized that significant differences in perceptions of DHRs exist between surgical and nonsurgical specialties, as well as junior and senior residents.

\section{Methods}

All residents currently enrolled in ACGME-accredited core residency programs at Mayo Clinic's campus in Rochester, Minnesota were eligible to participate in our cross-sectional survey. The Mayo Clinic Institutional Review Board approved the study.

We collected data from August 11 through October 1, 2014. Residents were invited through email to complete an anonymous electronic survey that included an informed consent statement on the first page. An email reminder was distributed midway through the survey period. Participation was voluntary, and residents received no incentive to participate. Study data were collected and managed using REDCap (Research Electronic Data Capture) electronic data capture tools hosted at Mayo Clinic. REDCap is a secure, Web-based application designed to support data capture for research studies [18].

We asked residents to provide information related to their demographic characteristics; satisfaction with and attitudes about DHRs; perceptions of culture and DHRs; perceptions of fatigue, medical errors, and relation to DHRs; and perceptions of the educational effect of DHRs. No individual survey questions were mandatory. We asked participants to record their specialty, and they were informed that specialty data would be reported only in aggregate specialty groupings. Data were not reported individually for core residencies, because the program size for some specialties was too small to ensure respondent confidentiality if reported independently.

Residency programs were categorized into 3 specialty groups for comparison: medical and pediatric (med/peds) (ie, internal medicine and subspecialties and pediatric and adolescent medicine); surgical (surgery) (ie, anesthesiology, dental specialties, neurologic surgery, obstetrics and gynecology, ophthalmology, orthopedic surgery, otorhinolaryngology, surgery and subspecialties, and urology); and other (other) (ie, dermatology, emergency medicine, family medicine, genetics, neurology, pathology and laboratory medicine, physical medicine and rehabilitation, psychiatry, radiation oncology, radiology, sports medicine, transitional year, and other). This categorization represents the subspecialty grouping applied by the Mayo School of Graduate Medical Education at Mayo Clinic in Minnesota. Residents were categorized as junior if they were in their first or second postgraduate year (PGY) and senior if they were in or beyond their third PGY.

We summarized survey responses using frequency counts and percentages. Percentages were calculated using the total number of nonmissing responses obtained for an individual question. Comparisons between junior and senior residents and among specialty types regarding satisfaction with DHRs 
Table 1 Demographic Characteristics of the 495 Survey Respondents

\begin{tabular}{|c|c|}
\hline Survey Question & Respondents, No. (\%) \\
\hline \multicolumn{2}{|l|}{ Age, y $(n=441)$} \\
\hline $20-24$ & $2(<1)$ \\
\hline $25-29$ & $202(46)$ \\
\hline $30-34$ & $179(41)$ \\
\hline $35-39$ & $34(8)$ \\
\hline $40-44$ & $9(2)$ \\
\hline $45-50$ & $8(2)$ \\
\hline$>50$ & $7(2)$ \\
\hline \multicolumn{2}{|l|}{$\operatorname{Sex}(n=440)$} \\
\hline Female & $176(40)$ \\
\hline Male & $264(60)$ \\
\hline \multicolumn{2}{|l|}{ Marital status $(n=441)$} \\
\hline Married/domestic partner & $291(66)$ \\
\hline Living with significant other & $34(8)$ \\
\hline Divorced & $8(2)$ \\
\hline Single, never married & $108(24)$ \\
\hline \multicolumn{2}{|l|}{ Children $(n=440)$} \\
\hline Yes & $161(37)$ \\
\hline No & $279(63)$ \\
\hline \multicolumn{2}{|l|}{ Medical school $(n=437)$} \\
\hline US medical graduate & $377(86)$ \\
\hline Foreign medical graduate & $60(14)$ \\
\hline \multicolumn{2}{|c|}{ Anticipated practice type $(n=440)$} \\
\hline Academic & $219(50)$ \\
\hline Private & $74(17)$ \\
\hline Unsure & $147(33)$ \\
\hline \multicolumn{2}{|l|}{ PGY $(n=438)$} \\
\hline 1 & $76(17)$ \\
\hline 2 & $81(18)$ \\
\hline 3 & $97(22)$ \\
\hline 4 & $62(14)$ \\
\hline 5 & $56(13)$ \\
\hline$\geq 6$ & $66(15)$ \\
\hline
\end{tabular}

Specialty, No. of respondents (\% of respondents; $\%$ of specialty responding) $(n=439)$

$\begin{array}{ll}\text { Anesthesiology } & 48(11 ; 81) \\ \text { Dermatology } & 9(2 ; 36) \\ \text { Emergency medicine } & 20(5 ; 80) \\ \text { Family medicine } & 17(4 ; 68) \\ \text { Genetics } & 1(<1 ; 50) \\ \text { Internal medicine and subspecialties } & 105(24 ; 61) \\ \text { Neurologic surgery } & 9(2 ; 41) \\ \text { Neurology } & 18(4 ; 67) \\ \text { Obstetrics and gynecology } & 14(3 ; 82) \\ \text { Ophthalmology } & 4(1 ; 33) \\ \text { Orthopedic surgery } & 31(7 ; 53) \\ \text { Otorhinolaryngology } & 2(<1 ; 10)\end{array}$

Table 1 Demographic Characteristics of the 495 Survey Respondents (Continued)

\begin{tabular}{ll}
\hline Survey Question & Respondents, No. (\%) \\
\hline Pathology and laboratory medicine & $14(3 ; 56)$ \\
Pediatric and adolescent medicine & $25(6 ; 60)$ \\
Physical medicine and rehabilitation & $15(3 ; 65)$ \\
Psychiatry & $19(4 ; 54)$ \\
Radiation oncology & $6(1 ; 50)$ \\
Radiology & $24(5 ; 46)$ \\
Surgery and subspecialties & $34(8 ; 34)$ \\
Urology & $9(2 ; 45)$ \\
Other & $15(3)$ \\
\hline Abbreviation: PGY postgraduate year
\end{tabular}

Abbreviation: $P G Y$ postgraduate year

and effect on training were evaluated with Wilcoxon rank sum and Kruskal-Wallis tests. Cronbach $\alpha$ was calculated for key survey questions that addressed similar concepts. Statistical analyses were performed with statistical software (version 9.3; SAS Institute Inc). $P<.05$ was considered statistically significant.

The reliability, validity, and psychometric properties of our instrument were addressed through a multifaceted approach. We conducted a literature review to identify existing survey research assessing resident perspectives on DHRs, which informed the construction of our survey instrument. A portion of our instrument was adapted from a previously published survey that targeted a national population of neurosurgical residents [12]. To address content validity, a multidisciplinary group of medical educators (in the specialties anesthesiology, emergency medicine, general surgery, internal medicine, obstetrics and gynecology, pediatrics, and psychiatry) reviewed and edited our survey questions. A pilot survey was conducted among these medical educators to eliminate questions that could be misinterpreted or could show bias. Pilot survey respondents provided feedback on participant solicitation and consent, content, question-and-answer wording, and the methodology of survey administration.

\section{Results}

\section{Demographic characteristics of respondents}

We identified 736 residents who met study criteria and invited them to participate in our survey. We received 495 responses (response rate, 67\%), of which 382 surveys $(77 \%)$ were completed in entirety. Residents from PGY-1 through PGY-6 and above were represented, and junior residents comprised 36\% of respondents. Women comprised $40 \%$ of our cohort, and $66 \%$ of respondents were married. Of the 439 respondents (89\%) who provided a specialty, $131(30 \%)$ were categorized as med/peds, $151(34 \%)$ as surgery, and $157(36 \%)$ as other. Table 1 summarizes the respondent demographic data. 
Satisfaction with and attitudes about duty hours

A majority of residents (78\%) reported satisfaction with the ACGME DHRs and reported that the requirements affect their training in an overall positive manner (73\%) (Cronbach $\alpha=.70)$. Junior residents were significantly more likely $(P \leq .001)$ than senior residents to report satisfaction with DHRs ( $84 \%$ vs $74 \%$ ) and an overall positive effect on their training ( $85 \%$ vs $66 \%$ ). Residents in surgical specialties were significantly less likely $(P \leq .001)$ to report satisfaction with DHRs $(66 \%)$ or an overall positive effect on training (63\%) than residents in $\mathrm{med} /$ peds $(87 \%$ and $76 \%)$ or other $(82 \%$ and $81 \%)$ specialties (Table 2).

\section{Perceptions of culture and duty hour violations}

Most respondents believed that DHRs were respected within their institution (93\%), are enforced (95\%), and were reflected in their work schedule (94\%) (Cronbach $\alpha=.92$ ) (Table 3). Some residents reported exceeding the 28 -h maximum duty hour requirement $(8 \%)$ or the 80 -h weekly maximum duty hour limit (11\%) more than rarely within the past year. Many residents believed that there are situations when a violation of DHRs may be justified $(80 \%)$. Few reported having been specifically asked to violate duty hour rules $(6 \%)$ either by a peer $(n=2)$, a senior resident $(n=7)$, an attending physician $(n=12)$, or some other person $(n=5)$.

\section{Perceptions of fatigue, medical errors, and relation to duty hours}

Most residents believed that fatigue (89\%) and patient handovers (90\%) contribute to adverse events (Table 4). A majority of residents believed DHRs reduced resident fatigue $(80 \%)$ and reduced the incidence of residents performing clinical duties while fatigued (74\%). Many residents believed that they $(71 \%)$ and their colleagues (66\%) were able to perceive when fatigue affected the care they provide. However, only $37 \%$ of residents believed that DHRs decreased medical errors, whereas $44 \%$ believed the standards had no effect on medical errors and 19\% believed medical errors were increased by DHRs. More than half of respondents (62\%) believed the standards decreased patient familiarity and continuity of care. Of respondents, $41 \%$ believed that patient handovers contributed more to adverse events than fatigue, compared with $27 \%$ who believed fatigue is the larger contributor.

\section{Perceptions of educational impact of duty hour requirements}

Among residents, 26\% indicated that DHRs enhanced their clinical educational experiences, whereas 33\% believed the requirements had no effect and $41 \%$ felt the requirements diminished their clinical experiences (Table 5). When questioned about perceptions of duty

Table 2 Resident Satisfaction and Comparison by PGY and Specialty

\begin{tabular}{|c|c|c|c|c|}
\hline \multirow[t]{2}{*}{ Survey Question } & \multicolumn{4}{|c|}{ Possible Survey Response } \\
\hline & Strongly agree & Agree & Disagree & Strongly disagree \\
\hline \multirow[t]{2}{*}{ I am satisfied with the current duty hour rules $(n=391)$} & $101(26)$ & $204(52)$ & $62(16)$ & $24(6)$ \\
\hline & Strongly positive & Positive & Negative & Strongly negative \\
\hline $\begin{array}{l}\text { Overall, I believe the current ACGME standards affect } \\
\text { my training in a_ way }(n=388)\end{array}$ & $34(9)$ & $249(64)$ & $89(23)$ & $16(4)$ \\
\hline I am satisfied with the current duty hour rules ${ }^{\mathrm{a}, \mathrm{b}}$ & Strongly agree & Agree & Disagree & Strongly disagree \\
\hline PGY 1 and PGY $2(n=144)$ & $48(33)$ & $74(51)$ & $18(13)$ & $4(3)$ \\
\hline PGY 3 and greater $(n=244)$ & $51(21)$ & $129(53)$ & $44(18)$ & $20(8)$ \\
\hline Med/peds $(n=119)$ & $38(32)$ & $65(55)$ & $14(12)$ & $2(2)$ \\
\hline Surgery $(n=140)$ & $20(14)$ & $73(52)$ & $32(23)$ & $15(11)$ \\
\hline Other $(n=130)$ & $42(32)$ & $65(50)$ & $16(12)$ & $7(5)$ \\
\hline $\begin{array}{l}\text { Overall, I believe the current ACGME standards affect } \\
\text { my training in a way,d }\end{array}$ & Strongly positive & Positive & Negative & Strongly negative \\
\hline PGY 1 and PGY $2(n=144)$ & $16(11)$ & $106(74)$ & $19(13)$ & $3(2)$ \\
\hline PGY 3 and beyond $(n=241)$ & $16(7)$ & $143(59)$ & $69(29)$ & $13(5)$ \\
\hline Med/peds $(n=118)$ & $11(9)$ & $79(67)$ & $26(22)$ & $2(2)$ \\
\hline Surgery $(n=138)$ & $9(7)$ & $77(56)$ & $39(28)$ & $13(9)$ \\
\hline Other $(n=130)$ & $13(10)$ & $92(71)$ & $24(18)$ & $1(1)$ \\
\hline
\end{tabular}

Abbreviations: ACGME Accreditation Council for Graduate Medical Education, med/peds, medical and pediatric, $P G Y$ postgraduate year

${ }^{a}$ Comparison by satisfaction table for PGY $1+2$ vs $P G Y \geq 3, P=.001$

${ }^{\mathrm{b}}$ Comparison by satisfaction table for Med/peds vs Surg vs Other, $P<.001$

'Comparison by effect on training table for PGY $1+2$ vs $P G Y \geq 3, P<.001$

${ }^{\mathrm{d} C}$ Comparison by effect on training table for Med/peds vs Surg vs Other, $P=.001$ 
Table 3 Resident Perceptions of Culture and Duty Hour Violations

\begin{tabular}{ll}
\hline Survey Question & \multicolumn{1}{c}{ Response, No. (\%) } \\
\hline The ACGME duty hour rules are respected at my institution $(n=390)$ \\
Strongly agree & $235(60)$ \\
Agree & $128(33)$ \\
Disagree & $21(5)$ \\
Strongly disagree & $6(2)$
\end{tabular}

The ACGME duty hour rules are consistently reflected in my work schedule $(n=390)$

$\begin{array}{ll}\text { Strongly agree } & 224(57) \\ \text { Agree } & 143(37) \\ \text { Disagree } & 19(5) \\ \text { Strongly disagree } & 4(1)\end{array}$

The ACGME duty hour rules are enforced at my institution $(n=390)$

$\begin{array}{ll}\text { Strongly agree } & 235(60) \\ \text { Agree } & 134(34) \\ \text { Disagree } & 16(4) \\ \text { Strongly disagree } & 5(1)\end{array}$

During the past year, I have exceeded the 28-h maximum work hour requirement ( $24 \mathrm{~h}$ continuous duty $+4 \mathrm{~h}$ for transition of care) $(n=390)$

$\begin{array}{ll}\text { Frequently } & 10(3) \\ \text { Occasionally } & 22(6) \\ \text { Rarely } & 56(14) \\ \text { Never } & 302(77)\end{array}$

During the past year, I have exceeded the 80-h maximum weekly hour limit $(n=382)$

$\begin{array}{ll}\text { Frequently } & 11(3) \\ \text { Occasionally } & 31(8) \\ \text { Rarely } & 79(21) \\ \text { Never } & 261(68)\end{array}$

During the past year, I failed to have 1 day per week free of duty (averaged over $4 \mathrm{wk})(n=389)$

$\begin{array}{ll}\text { Frequently } & 14(4) \\ \text { Occasionally } & 16(4) \\ \text { Rarely } & 24(6) \\ \text { Never } & 335(86)\end{array}$

Are there situations in which you believe it would be appropriate to violate duty hour rules? $(n=386)$

$$
\text { Yes } 307(80)
$$$$
\text { No } 79 \text { (20) }
$$

Have you ever been asked to violate duty hour rules? $(n=388)$

Yes 25 (6)

No $363(94)$
Table 3 Resident Perceptions of Culture and Duty Hour Violations (Continued)

\begin{tabular}{lc}
\hline Survey Question & Response, No. (\%) \\
\hline If so, by whom were you asked to violate duty hour rules? $(n=26)$ \\
Peer & $2(8)$ \\
Senior resident & $7(27)$ \\
Attending physician & $12(46)$ \\
Other & $5(19)$ \\
\hline
\end{tabular}

Abbreviation: ACGME Accreditation Council for Graduate Medical Education

hour effects on board examinations, academic productivity, and scheduled educational conferences, opinions were mixed. Opinions about the 16 -h work limit for interns also varied; however, a majority of residents (73\%) believed that their specialty should be subject to the same DHRs as other specialties.

\section{Discussion}

In this cross-sectional survey study of residents enrolled in all ACGME-accredited core residency programs at a large academic medical center, we found that a majority of residents were satisfied with the ACGME DHRs and perceived them as having an overall positive effect on their training.

Residents training in specialties categorized as surgical were significantly less likely to be satisfied with the DHRs or to report DHRs having a positive effect on their training than those categorized as medical and pediatric or other. Our results mirror an existing theme in the medical education literature, wherein concerns about the DHRs impact on surgical training in particular are highlighted [12, 15, 19-21]. Prior assessments of attitudes about DHRs by specialty have been reported, although among smaller samples and generally comparing 2 individual specialties. A multicenter survey study of 159 general surgery and internal medicine trainees from 3 centers demonstrated similar opinions about DHRs [22]. A more recent study of 202 general surgery and internal medicine residents and faculty compared a subset of 49 resident respondents and found that surgical residents favored DHRs significantly less than their internal medicine counterparts [17]. Our findings indicate that residents in specialties broadly categorized as surgical view the DHRs significantly less favorably than their colleagues in nonsurgical specialties. We chose not to report findings by individual specialty to ensure the confidentiality of respondents who are enrolled in programs with few trainees.

Residents in advanced stages of training, defined as PGY-3 and above, were also significantly less likely to be satisfied with DHRs or to report overall benefit to their training than those at a PGY-1 or 2 level. A national survey of family medicine residents similarly found that 
Table 4 Resident Perceptions of Fatigue, Medical Errors, and Relation to Duty Hours

\begin{tabular}{ll}
\hline Survey Question & Respondents, No. (\%) \\
\hline $\begin{array}{l}\text { I believe the current ACGME standards help reduce resident fatigue } \\
(n=385)\end{array}$ \\
Strongly agree & $61(16)$ \\
Agree & $248(64)$ \\
Disagree & $66(17)$ \\
Strongly disagree & $10(3)$
\end{tabular}

I believe that I can consistently tell when fatigue is adversely affecting my clinical performance $(n=386)$

$\begin{array}{ll}\text { Strongly agree } & 52(13) \\ \text { Agree } & 221(57) \\ \text { Disagree } & 102(26) \\ \text { Strongly disagree } & 11(3)\end{array}$

I believe that my resident colleagues can consistently tell when fatigue is adversely affecting their clinical performance $(n=388)$

$\begin{array}{ll}\text { Strongly agree } & 22(6) \\ \text { Agree } & 234(60) \\ \text { Disagree } & 120(31) \\ \text { Strongly disagree } & 12(3)\end{array}$

I believe the ACGME duty hour rules decrease the frequency of residents performing clinical duties while fatigued $(n=387)$

\begin{tabular}{ll} 
Strongly agree & $38(10)$ \\
Agree & $250(65)$ \\
Disagree & $85(22)$ \\
Strongly disagree & $14(4)$ \\
I believe the current ACGME standards & \\
\cline { 2 - 2 } Markedly increase & $15(4)$ \\
Increase & $61(16)$ \\
Do not effect & $171(44)$ \\
Decrease & $126(32)$ \\
Markedly decrease & $17(4)$ \\
I believe the current ACGME standards $n=390)$ \\
\cline { 2 - 2 } and continuity of care $(n=389)$ & $7(2)$ \\
Markedly increase & $26(7)$ \\
Increase & $116(30)$ \\
Do not effect & $192(49)$ \\
Decrease & $48(12)$ \\
Markedly decrease & $237(61)$ \\
I believe that resident fatigue contributes to adverse events $(n=390)$ \\
Strongly agree & $112(29)$ \\
Agree & $235(60)$ \\
Disagree & $39(10)$ \\
Strongly disagree & $4(1)$
\end{tabular}

Table 4 Resident Perceptions of Fatigue, Medical Errors, and Relation to Duty Hours (Continued)

\begin{tabular}{ll}
\hline Survey Question & Respondents, No. (\%) \\
\hline Disagree & $38(10)$ \\
Strongly disagree & $2(1)$
\end{tabular}

Regarding the contribution of fatigue and handovers to adverse events, which of the following do you believe contribute more significantly to adverse events? $(n=389)$

$\begin{array}{ll}\text { Fatigue } & 105(27) \\ \text { Handovers } & 158(41) \\ \text { Both contribute equally } & 121(31) \\ \text { Neither contribute } & 5(1)\end{array}$

During my training, I have made an error in patient care at the conclusion of an extended shift ( $>24$ h) $(n=387)$

$\begin{array}{ll}\text { Yes } & 80(21) \\ \text { No } & 307(79)\end{array}$

If so, did the error result in patient harm? $(n=100)$

$$
\begin{array}{ll}
\text { Yes } & 10(10) \\
\text { No } & 90(90)
\end{array}
$$

During my training, I have been involved in a motor vehicle collision or potentially life-threatening event while leaving the hospital after an extended shift (>24 h) $(n=387)$

\begin{tabular}{ll} 
Yes & $16(4)$ \\
No & $371(96)$ \\
\hline Abbreviation: ACGME Accreditation Council for Graduate Medical Education
\end{tabular}

PGY-1 residents viewed DHRs more favorably than those in the PGY-2 year (25\% vs 23\%) [23]. That our finding is of greater magnitude may reflect the comparison of junior residents to those at considerably more advanced stages of training. The Flexibility in Duty Hour Requirements for Surgical Trainees (FIRST) trial, a prospective, randomized trial assessing impact of duty hour flexibility for general surgical trainees, also demonstrated increased concerns among senior residents, compared with junior residents, about negative effects of standard DHRs on patient safety and continuity of care [24].

Despite the differences we observed between the surgical versus nonsurgical disciplines and senior versus junior residents, it is worth stating that a majority of these subgroups did ultimately report overall satisfaction with the DHRs. Most respondents also indicated that the DHRs were respected and enforced by their institution. While most indicated that situations do exist where violation of DHRs is justified, few reported more than sporadic violations within the past year.

Although a majority of respondents believed the DHRs mitigate resident fatigue, only $37 \%$ believed that the requirements decreased medical errors. More than one-half of respondents believed that DHRs did not impact $(44 \%)$ or increased (19\%) medical errors. Our findings are congruent with a study using a grounded-theory analysis of resident comments, that found residents did 
Table $\mathbf{5}$ Resident Perceptions of Educational Impact of Duty Hour Requirements

\begin{tabular}{|c|c|}
\hline Survey Question & Respondents, No. (\%) \\
\hline \multicolumn{2}{|c|}{$\begin{array}{l}\text { I believe the current ACGME standards___ residents' clinical } \\
\text { educational experiences }(n=388)\end{array}$} \\
\hline Markedly enhance & $19(5)$ \\
\hline Enhance & $81(21)$ \\
\hline Do not effect & $127(33)$ \\
\hline Diminish & $129(33)$ \\
\hline Markedly diminish & $32(8)$ \\
\hline \multicolumn{2}{|c|}{$\begin{array}{l}\text { I believe the current ACGME standards } \\
\text { for specialty board examinations }(n=386)\end{array}$} \\
\hline Markedly enhance & $12(3)$ \\
\hline Enhance & $104(27)$ \\
\hline Do not effect & $185(48)$ \\
\hline Diminish & $67(17)$ \\
\hline Markedly diminish & $18(5)$ \\
\hline \multicolumn{2}{|c|}{$\begin{array}{l}\text { I believe the current ACGME standards } \_ \text {residents' academic } \\
\text { productivity (publications, presentations, attendance and participation at } \\
\text { national conferences) }(n=384)\end{array}$} \\
\hline Markedly enhance & $34(9)$ \\
\hline Enhance & $157(41)$ \\
\hline Do not effect & $152(40)$ \\
\hline Diminish & $34(9)$ \\
\hline Markedly diminish & $7(2)$ \\
\hline
\end{tabular}

I believe the current ACGME standards residents' ability to attend daily or weekly educational conferences, such as didactics, morning report, Grand Rounds, and noon conferences $(n=387)$

$\begin{array}{ll}\text { Markedly enhance } & 28(7) \\ \text { Enhance } & 112(29) \\ \text { Do not effect } & 151(39) \\ \text { Diminish } & 84(22) \\ \text { Markedly diminish } & 12(3)\end{array}$

I believe PGY-1 residents should work no more than $16 \mathrm{~h}$ of continuous duty $(n=386)$

$\begin{array}{ll}\text { Strongly agree } & 62(16) \\ \text { Agree } & 128(33) \\ \text { Disagree } & 133(34) \\ \text { Strongly disagree } & 63(16)\end{array}$

I believe my specialty should be subject to the same duty hour regulations as residents in other specialties $(n=386)$

$\begin{array}{ll}\text { Strongly agree } & 78(20) \\ \text { Agree } & 205(53) \\ \text { Disagree } & 61(16) \\ \text { Strongly disagree } & 42(11)\end{array}$

Abbreviations: ACGME Council for Graduate Medical Education, $P G Y$ postgraduate year not associate patient safety with DHR compliance [16, $25]$. This may be in part due to a perception that patient handovers have increased and continuity of care has decreased. Our study does not directly address this question; however, we did find that a majority of residents believed that patient handovers contribute equally or more significantly to adverse patient events than fatigue. Arora and colleagues [10] found interns' perceptions of the tradeoff between lack of care continuity and fatigue to depend largely on clinical context. Other studies have demonstrated that residents cite handovers as an important factor contributing to adverse events $[15,26]$, and existing empirical studies and national resident surveys have demonstrated a significant increase in the number of patient handovers following implementation of DHRs [13, 27].

Only $26 \%$ of residents perceived the DHRs to have a positive impact on their clinical educational experience. Prior studies have demonstrated findings of perceived reductions in bedside teaching, clinical educational experiences [22], and surgical opportunities [12, 20]. However, it is of importance to note that a large review of DHRs among surgical residents revealed no adverse effects on residents' operative experience [28]. A subsequent systematic review associated the 16-h duty maximums with a nonsignificant trend toward worsened educational outcomes [21]. Similarly, the FIRST trial showed no significant difference between standard and flexible duty hour groups with regard to overall educational quality [24].

Strengths of our study are the large sample size and high resident response rate. In addition, we surveyed residents currently enrolled in all ACGME-accredited core residency programs at a large academic institution, and included residents at all levels of training within those programs. We also endeavored to conduct a thorough evaluation of the survey instrument by piloting our survey among experienced medical educators prior to its implementation.

Limitations of our study include a cross-sectional study design, single-institution sampling, and a subjective assessment by the study subject relating to Level 1 outcomes [29]. Because our survey was optional, it may also be limited by sampling bias. Despite the high response rate, it is possible that those who opted not to take the survey are dissimilar from those who chose to respond. Future work should focus on multi-institutional assessments that would allow for greater generalizability and an understanding of resident perceptions of DHRs across the specific individual specialties. Further, use of qualitative research methods, such as those used by Philibert [16], may prove useful in determining the underlying reasons for residents' perceptions of DHRs [30]. 


\section{Conclusion}

In this cross-sectional survey study of residents enrolled in all ACGME-accredited core residency programs at a large academic medical center, a majority of respondents were satisfied with the current ACGME DHRs and believed they affected their training in an overall positive manner. Residents in surgical specialties and those in advanced stages of training were significantly less likely to view DHRs favorably, although in these subgroups as well, a majority of the respondents did report overall satisfaction with the DHRs.

\section{Abbreviations \\ ACGME: Accreditation Council for Graduate Medical Education; DHR: Duty hour requirement; FIRST: Flexibility in Duty Hour Requirements for Surgical Trainees; med/peds: Medical and pediatric; PGY: Postgraduate year; REDCap: Research electronic data capture}

\section{Acknowledgments}

Not applicable.

\section{Funding}

None.

\section{Availability of data and materials}

The datasets generated and analyzed during the present study are not publicly available because of Mayo Clinic College of Medicine and Science protections governing trainee-related data. Data are available from the corresponding author on reasonable request following explicit approval by Mayo Clinic College of Medicine and Science.

\section{Publisher}

To expedite proof approval, send proof via email to scipubs@mayo.edu. C2017 Mayo Foundation for Medical Education and Research.

\section{Previous presentations}

Presented in oral and poster formats at the 2015 Accreditation Council for Graduate Medical Education Annual Educational Conference, San Diego, California, February 26 to March 1, 2015, and in poster format at the 2015 Society for Academic Emergency Medicine Annual Meeting, San Diego, California, May 14, 2015.

\section{Authors' contributions}

BJS wrote the manuscript; conducted the data interpretation and prepared the manuscript's Results and Discussion sections; and had full access to all study data and takes responsibility for the integrity of the data and the accuracy of the data analysis. DMS conducted the survey and wrote the manuscript. CML conducted and is responsible for the data analysis. SHR conducted the data interpretation and prepared the manuscript's Results and Discussion sections. JEC wrote the manuscript, had full access to all study data, and takes responsibility for the integrity of the data and the accuracy of the data analysis. All authors contributed to the study conceptualization and design and read and approved the final manuscript.

\section{Ethics approval and consent to participate}

The Mayo Clinic Institutional Review Board deemed this study exempt on July 8, 2014 (No. 13-002049). Informed consent was obtained from survey participants.

\section{Consent for publication}

Not applicable.

\section{Competing interests}

The authors declare that they have no competing interests.

\section{Publisher's Note}

Springer Nature remains neutral with regard to jurisdictional claims in published maps and institutional affiliations.

\section{Author details}

'Department of Emergency Medicine, Mayo Clinic, 200 First St SW, Rochester, MN 55905, USA. ²Division of Biomedical Statistics and Informatics, Mayo Clinic, Rochester, MN, USA. ${ }^{3}$ Department of Anesthesiology, Mayo Clinic, Rochester, MN, USA

Received: 3 March 2017 Accepted: 31 October 2017

Published online: 10 November 2017

\section{References}

1. Kohn LT, Corrigan JM, Donaldson MS, editors. To err is human: building a safer health system. Washington (DC): National Academy Press; 2000.

2. Philibert I, Chang B, Flynn T, Friedmann P, Minter R, Scher E, et al. The 2003 common duty hour limits: process, outcome, and lessons learned. J Grad Med Educ. 2009:1(2):334-7.

3. Philibert I, Friedmann P, Williams WT; Accreditation Council for Graduate Medical Education (ACGME) Work Group on Resident Duty Hours. New requirements for resident duty hours. JAMA 2002;288(9):1112-1114.

4. Ulmer C, Miller Wolman D, Johns MME, editors; Committee on Optimizing Graduate Medical Trainee (Resident) Hours and Work Schedules to Improve Patient Safety. Resident duty hours: enhancing sleep, supervision and safety. Washington (DC): National Academies Press; 2009.

5. Nasca TJ, Day SH, Amis ES Jr, ACGME Duty Hour Task Force. The new recommendations on duty hours from the ACGME task force. N Engl J Med. 2010;363(2):e3. Epub 2010 Jun 23

6. Dawson D, Reid K. Fatigue, alcohol and performance impairment. Nature. 1997;388(6639):235.

7. Koslowsky M, Babkoff $\mathrm{H}$. Meta-analysis of the relationship between total sleep deprivation and performance. Chronobiol Int. 1992;9(2):132-6.

8. Lim J, Dinges DF. A meta-analysis of the impact of short-term sleep deprivation on cognitive variables. Psychol Bull. 2010;136(3):375-89.

9. Lockley SW, Cronin JW, Evans EE, Cade BE, Lee CJ, Landrigan CP, Harvard Work Hours, Health and Safety Group, et al. Effect of reducing interns' weekly work hours on sleep and attentional failures. N Engl J Med. 2004;351(18):1829-37.

10. Arora VM, Farnan JM, Lypson ML, Anderson RA, Prochaska MH, Humphrey HJ. Incoming interns' perspectives on the institute of medicine recommendations for residents' duty hours. J Grad Med Educ. 2010;2(4):536-40.

11. Jagsi R, Weinstein DF, Shapiro J, Kitch BT, Dorer D, Weissman JS. The accreditation Council for Graduate Medical Education's limits on residents' work hours and patient safety: a study of resident experiences and perceptions before and after hours reductions. Arch Intern Med. 2008;168(5):493-500.

12. Fargen KM, Chakraborty A, Friedman WA. Results of a national neurosurgery resident survey on duty hour regulations. Neurosurgery. 2011;69(6):1162-70.

13. Desai SV, Feldman L, Brown L, Dezube R, Yeh HC, Punjabi N, et al. Effect of the 2011 vs 2003 duty hour regulation-compliant models on sleep duration, trainee education, and continuity of patient care among internal medicine house staff: a randomized trial. JAMA Intern Med. 2013;173(8):649-55.

14. Kort KC, Pavone LA, Jensen E, Haque E, Newman N, Kittur D. Resident perceptions of the impact of work-hour restrictions on health care delivery and surgical education: time for transformational change. Surgery. 2004;136(4):861-71.

15. Philibert I, Nasca T, Brigham T, Shapiro J. Duty-hour limits and patient care and resident outcomes: can high-quality studies offer insight into complex relationships? Annu Rev Med. 2013;64:467-83. Epub 2012 Oct 26

16. Philibert I. Resident perspectives on duty hour limits and attributes of their learning environment. BMC Med Educ. 2014;14(Suppl 1):S7. Epub 2014 Dec 11

17. Tierney WS, Elkin RL, Nielsen CD. Quantitative and qualitative perceptions of the 2011 residency duty hour restrictions: a multicenter, multispecialty cross-sectional study. BMC Medical Educ. 2015:15:57.

18. Harris PA, Taylor R, Thielke R, Payne J, Gonzalez N, Conde JG. Research electronic data capture (REDCap): a metadata-driven methodology and workflow process for providing translational research informatics support. J Biomed Inform. 2009:42(2):377-81. Epub 2008 Sep 30

19. Harris JD, Staheli G, LeClere L, Andersone D, McCormick F. What effects have resident work-hour changes had on education, quality of life, and safety? A systematic review. Clin Orthop Relat Res. 2015;473(5):1600-8.

20. Fitzgibbons SC, Chen J, Jagsi R, Weinstein D. Long-term follow-up on the educational impact of ACGME duty hour limits: a pre-post survey study. Ann Surg. 2012;256(6):1108-12.

21. Ahmed N, Devitt KS, Keshet I, Spicer J, Imrie K, Feldman L, et al. A systematic review of the effects of resident duty hour restrictions in surgery: 
impact on resident wellness, training, and patient outcomes. Ann Surg. 2014;259(6):1041-53.

22. Myers JS, Bellini LM, Morris JB, Graham D, Katz J, Potts JR, et al. Internal medicine and general surgery residents' attitudes about the ACGME duty hours regulations: a multicenter study. Acad Med. 2006;81(12):1052-8.

23. Lo V, Ward C. 2011 ACGME duty hour week proposal: a national survey of family medicine residents. Fam Med. 2011;43(5):318-24.

24. Yang AD, Chung JW, Dahlke AR, Biester T, Quinn CM, Matulewicz RS, et al. Differences in resident perceptions by postgraduate year of duty hour policies: an analysis from the flexibility in duty hour requirements for surgical trainees (FIRST) trial. J Am Coll Surg. 2017;224(2):103-12. Epub 2016 Nov 4

25. Glaser BG, Strauss AL. The discovery of grounded theory: strategies for qualitative research. Chicago: Aldine Publishing; 1967. p. 271.

26. Jagsi R, Kitch BT, Weinstein DF, Campbell EG, Hutter M, Weissman JS. Residents report on adverse events and their causes. Arch Intern Med. 2005;165(22):2607-13.

27. Drolet BC, Christopher DA, Fischer SA. Residents' response to duty-hour regulations: a follow-up national survey. N Engl J Med. 2012;366(24):e35. Epub 2012 May 30

28. Jamal MH, Rousseau MC, Hanna WC, Doi SA, Meterissian S, Snell L. Effect of the ACGME duty hours restrictions on surgical residents and faculty: a systematic review. Acad Med. 2011;86(1):34-42.

29. Reed DA, Cook DA, Beckman TJ, Levine RB, Kern DE, Wright SM. Association between funding and quality of published medical education research. JAMA. 2007:298(9):1002-9.

30. Patton MQ. Qualitative evaluation and research methods. 2nd ed. Newbury Park: Sage Publications; 1990. p. 532.

\section{Submit your next manuscript to BioMed Central and we will help you at every step:}

- We accept pre-submission inquiries

- Our selector tool helps you to find the most relevant journal

- We provide round the clock customer support

- Convenient online submission

- Thorough peer review

- Inclusion in PubMed and all major indexing services

- Maximum visibility for your research

Submit your manuscript at www.biomedcentral.com/submit 